\title{
ЭКСПЕРИМЕНТАЛЬНОЕ ОПРЕДЕЛЕНИЕ РАДИУСА ЗОНЫ ЭФФЕКТИВНОГО ТРЕЩИНООБРАЗОВАНИЯ ПРИ ТОРПЕДИРОВАНИИ ПОРОД КАРНАЛЛИТ-ГАЛИТОВОГО СЛОЯ ПЛАСТА КАЛИЙНО- МАГНИЕВЫХ СОЛЕЙ В УСЛОВИЯХ РУДНИКА ГРЕМЯЧИНСКОГО ГОКА
}

\author{
E.A. HECTEPOB \\ Горный институт УрО РАН, г. Пермь
}

\begin{abstract}
Аннотация: Статья посвящена газодинамическим явлениям на Гремячинском месторождении калийномагниевых солей. Приведены общие данные по расположению и строению месторождения. Представлены результаты работ по изучению газоносности и газодинамических характеристик, слагающих месторождение как показателей выбросоопасности. Приведены случаи газодинамических явлений, отмеченные на месторождении. Рассмотрены условия их проявления и определены общие признаки, позволяющие их классифицировать, как внезапные выбросы породы и газа. На основании имеющегося опыта предотвращения газодинамических явлений при разработке карналлитовых пластов предложена комбайновая проходка подготовительных выработок с предварительной обработкой массива горных пород способом передового торпедирования шпуровыми зарядами. Представлена методика определения радиуса эффективного трещинообразования, которая заключается в сравнении газопроницаемости карналлит-галитовых пород до и после торпедирования массива. Приведены результаты экспериментальных работ по определению радиуса эффективного трещинообразования в породах карналлит-галитового слоя, а также результаты контроля эффективности торпедирования массива по показателю воздухопоглощения. На основе экспериментальных данных определен параметр, определяющий расстояние между шпурами для составления паспортов взрывных работ на торпедировании массива карналлит-галитовых пород.

Ключевые слова: калийный рудник, газодинамическое явление, карналлит-галитовый слой, радиус эффективного трещинообразования, торпедирование массива.
\end{abstract}

\section{Введение}

Гремячинское месторождение калийных солей расположено на территории Котельниковского района Волгоградской области, в 150 км к юго-западу от г. Волгограда, в 20 км к северо-востоку от районного центра г. Котельниково, на левобережной части бассейна нижнего течения р. Дон. В пределах месторождения выделяется один продуктивный сильвинитовый пласт. В общем плане залежь погружается с юго-запада на северо-восток месторождения, абсолютные отметки кровли промышленного сильвинитового пласта изменяются от минус 981,3 м до минус 1191,3 м. Мощность продуктивного сильвинитового пласта изменяется от 2,48 м до 21,46 м. На большей части лицензионного участка составляет 6-10 м. Ниже продуктивного сильвинитового пласта залегает слой карналлит-галитовых пород.

Как известно, карналлитовые породы являются одними из наиболее опасных по внезапным выбросам породы и газа.

Изучение газодинамических характеристик и газоносности по свободным газам, как показателей выбросоопасности карналлит-галитовых пород, показало, что она изменяется от 0,02 $\mathrm{m}^{3} / \mathrm{M}^{3}$ до $0,32 \mathrm{~m}^{3} / \mathrm{m}^{3}$, при среднем значении $0,17 \mathrm{~m}^{3} / \mathrm{M}^{3}$. Газоносность по свободным газам карналлитовых пород изменяется от $0,15 \mathrm{~m}^{3} / \mathrm{m}^{3}$ до $1,16 \mathrm{~m}^{3} / \mathrm{m}^{3}$, при среднем значении $0,30 \mathrm{~m}^{3} / \mathrm{m}^{3}$. Компонентный состав свободных газов: $\mathrm{CH}_{4}-32,31 \% ; \mathrm{H}_{2}-4,69 \% ; \mathrm{C}_{2} \mathrm{H}_{6}-0,436 \% ; \mathrm{C}_{3} \mathrm{H}_{8}-$ $0,020 \% ; \mathrm{iC}_{4} \mathrm{H}_{10}-0,001 \% ; \mathrm{nC}_{4} \mathrm{H}_{10}-0,005 \% ; \mathrm{N}_{2}-62,51 \% ; \mathrm{CO}_{2}$ и другие газы - $0,02 \%$. Средняя газоносность по условному метану составляет $0,48 \mathrm{~m}^{3} / \mathrm{m}^{3}$. Суммарное содержание горючих газов (метан + водород) составляет $37,01 \%$. Суммарное содержание углеводородов метанового ряда $-0,463 \%$. Газоносность карналлитовых пород пласта калийно-магниевых солей по связанным газам изменяется от 0,011 до $0,072 \mathrm{~m}^{3} / \mathrm{m}^{3}$, при среднем значении $0,039 \mathrm{~m}^{3} / \mathrm{m}^{3}$. По компонентному составу связанные газы - метаново-азотные. Максимальное содержание метана в составе связанных газов - 24,10\%. В составе связанных газов карналлитовых пород также обнаружен водород, максимальное значение которого достигает $0,65 \%$. При этом суммарное содержание углеводородов метанового ряда достигает $0,21 \%$, содержание азота $-74,98 \%$. Следовательно, можно угверждать, что породы карналлит-галитового слоя содержат свободные газы и являются потенциально опасными по выбросам породы и газа

Согласно технической документации все подготовительные и очистные выработки предусмотрено располагать в пределах продуктивного сильвинитового пласта, однако при проходке большинства подготовительных выработок, в силу природной складчатости, забоями выработок вскрывался слой карналлит-галитовых пород (рис. 1). Проходка выработок осуществляется комбайнами «Урал-20Р». 

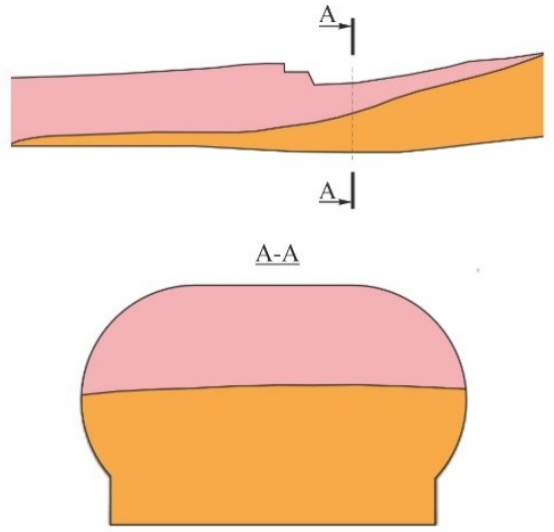

- Сильвинитовая порода

Рис. 1. Геологический разрез по разведочному штреку
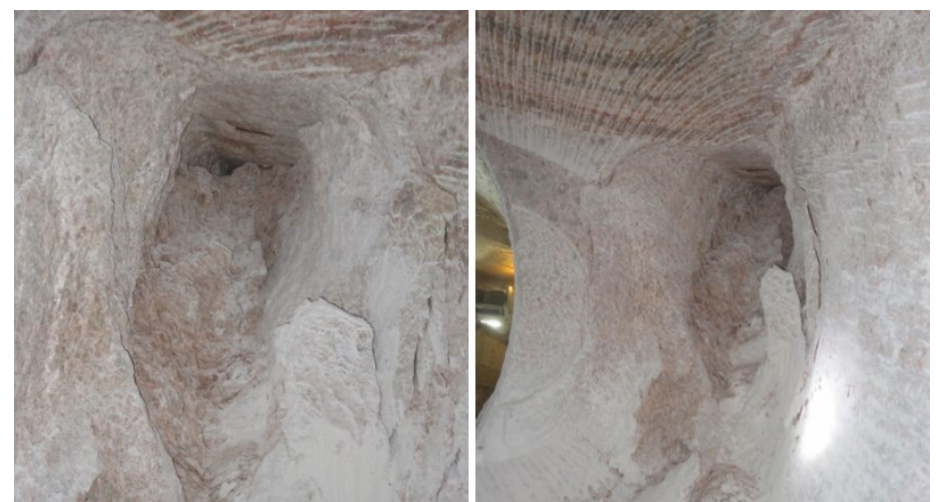

Рис. 2. Полость в стенке разведочного штрека № 2

В последнее время в пределах Гремячинского месторождения стали отмечаться случаи выбросы породы и газа при вскрытии пород карналлит-галитового слоя (рис.2). Природа выбросов соли и газа при проходке горных выработок по породам карналлит-галитового слоя обусловлена наличием локальных газонасыщенных зон, формирование которых происходило, по-видимому, при эпигенетических (вторичных) процессах, обусловленных складкообразованием и миграцией газонасыщенных водных растворов, которая сопровождалась аккумуляцией газов на локальных участках пород с пониженной прочностью.

Согласно пункту 1.2.16. «Специальных мероприятий по безопасному ведению горных работ в условиях газового режима на Гремячинском месторождении калийных солей» все рабочие зоны, выработки которых частично или полностью проходятся по карналлит-галитовому слою пласта калийно-магниевых солей, относятся к 3 группе опасности.

Проходка выработок по карналлит-галитовому слою должна осуществляться в соответствии с требованиями нормативной документации по безопасному ведению горных работ - «Технологического регламента по механизированной проходке горных выработок по карналлит-галитовому слою пласта калийно-магниевых солей в условиях рудника Гремячинского горнообогатительного комбината».

Технологическим регламент предусматривает передовое торпедирование (профилактическая обработка) массива карналлит-галитовых пород. В связи с этим экспериментальными работами необходимо определить расстояние вокруг шпура, на которое распространяются трещины (радиус эффективного трещинообразования).

\section{Методика определения радиуса эффективного трещинообразования}

В настоящее время торпедирование карналлитовых пород для предотвращения внезапных выбросов зарекомендовало себя весьма эффективным способом на рудниках Верхнекамского месторождения калийных солей [1-4]. Методика определения радиуса зоны эффективного трещинообразования $R_{\text {э }}$ заключается в сравнении газопроницаемости карналлит-галитовых пород до и после торпедирования [5-8].

Для определения газопроницаемости карналлита в массиве в исследуемой зоне бурят два параллельных шпура: рабочий 1 и контрольный 2 на расстоянии 25 см друг от друга (рис. 3). Длина шпуров должна быть такой, чтобы исключалось влияние горных работ на состояние пород и составляла бы не менее 2,5 м. Шпуры герметизируются механическими (или другими) герметизаторами 3 на глубину не менее 1,5 м. Герметизаторы должны обеспечивать надежную герметизацию шпуров. Длина газовой камеры 9 должна составлять 0,3-0,5 м, длина участка герметизации - не менее 0,3 м.

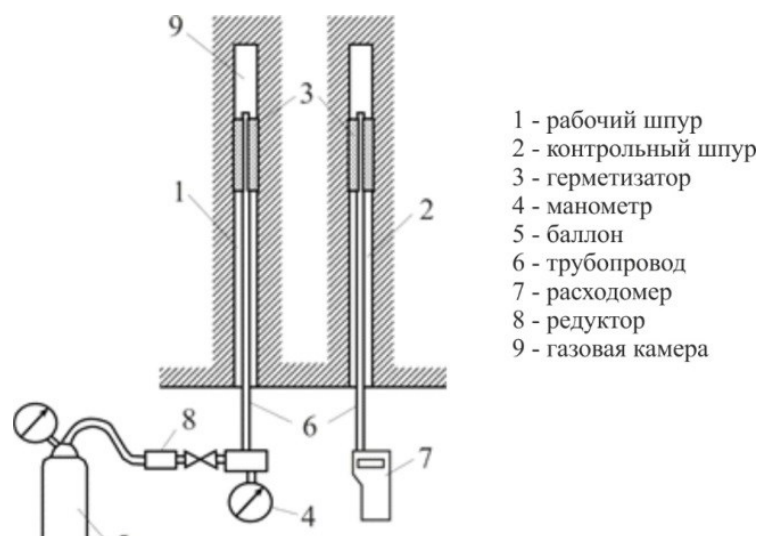

Рис. 3. Схема к определению коэффициента газопроницаемости 
К герметизатору рабочего шпура присоединяется манометр для определения давления газа в газовой камере. Газ под давлением 0,5-1,5 МПа подается в шпур по трубопроводу. К штуцеру герметизатора контрольного шпура присоединяется расходомер (газовый счетчик). После подачи в рабочий шпур газа при определенном давлении измеряют расход газа из контрольной скважины. Таких измерений делают не менее 3-х при разном давлении в рабочем шпуре.

Коэффициент газопроницаемости определяется по формуле:

$$
K=\frac{4 \times \mathrm{g} \times \mathrm{R} \times \mathrm{P}_{\text {ат }}}{3,3 \times 10^{-3} \times\left(\mathrm{P}_{0}^{2}-\mathrm{P}_{\mathrm{aT}}^{2}\right)}, M Д
$$

где $g$ - объёмный расход газа, ${ }^{3} /$ сутки $; R$ - расстояние между стенками рабочего и контрольного шпуров, принимается равным $0,25 \mathrm{м} ; P_{\text {ат }}$ - атмосферное давление,

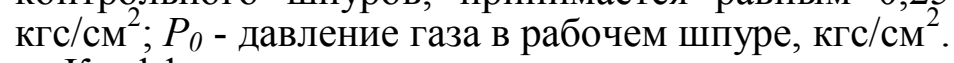

Коэффициент газопроницаемости пласта до торпедирования определяется как среднее арифметическое не менее чем из 3-х измерений.

Перед выполнением измерений определяется возможная фильтрация природного газа (фоновая) в контрольный шпур из массива. В этом случае, истинный объемный расход рабочего газа через контрольный шпур равен разности значений объемного расхода газа из шпура, замеренного в процессе измерений, и фонового расхода.

Определение коэффициента газопроницаемости после торпедирования заключается в следующем (рисунок 4).

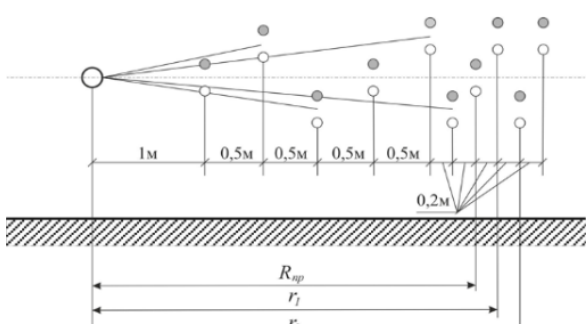

Рис. 4. Схема к определению коэффициента газопроницаемости после торпедирования

В массиве бурят шпур (скважину) нужного диаметра глубиной не менее трех метров и производят его торпедирование. Затем, отступив от шпура (скважины) на один метр бурят рабочий и контрольный шпуры для определения газопроницаемости с интервалом, начиная от 0,5 м до 0,2 м на границе зоны приближенного радиуса трещинообразования $\mathrm{R}_{\mathrm{np}}$, который определяется как $R_{n p}=35 \times \cdot \mathrm{r}_{3}$, где $\mathrm{r}_{3}$ - радиус заряда ВВ в шпуре (скважине).

Располагать шпуры следует по разным лучам радиуса как показано на рисунке 2. Бурение шпуров должно производиться с помощью приспособлений, обеспечивающих параллельность рабочего и контрольного шпуров. Расстояние между парами шпуров не должно быть менее 0,5 м.

За радиус зоны эффективного трещинообразования принимается средний радиус между предыдущим и последующим, где газопроницаемость близка к коэффициенту газопроницаемости до торпедирования, умноженным на коэффициент запаса, т.е.

$R_{\text {э }}=K \times \frac{r_{1}+r_{2}}{2}$ где $K$ - коэффициент запаса, $K=0,9$.

Одновременно с определением радиуса зоны эффективного трещинообразования проводится контроль эффективности торпедирования массива. После нагнетания в контрольный шпур газа под давлением 0,5-1,5 МПа (5-15 атм.), подачу газа перекрывают и секундомером засекают время падения давления в шпуре. Суммируя объем измерительной камеры в шпуре $(0,75$ л), герметизатора и трубопровода $(0,25$ л) с учетом установленного давления определяется объем закаченного газа. Отношение общего объема сжатого газа к времени падения давления в шпуре является показателем воздухопоглощения пород исследуемого массива.

\section{Результаты экспериментального определения радиуса зоны эффективного трещинообразования}

Для определения газопроницаемости карналлит-галитовых пород в массиве в правой стенке вспомогательного транспортного уклона № 2 шахтного поля рудника Гремячинского ГОКа на глубину 3,0 м пробурены два параллельных шпура: рабочий и контрольный на расстоянии 25 см друг от друга. Шпуры герметизировались механическими герметизаторами на глубину не менее 1,5 м. К герметизатору рабочего шпура присоединялся манометр для определения давления газа в газовой камере. Газ под давлением 5-15 атм подавался в шпур по трубопроводу. К штуцеру герметизатора контрольного шпура присоединялся расходомер (DPI 740). После подачи в рабочий шпур газа при определенном давлении измерялся расход газа из контрольного шпура. Таких измерений проведено 3 при давлении в рабочем шпуре 10 атм. 
В левой стенке вспомогательного транспортного уклона № 2 на расстоянии 10 м друг от друга пробурены 3 торпедируемых шпура диаметром 42 мм глубиной 4 м, масса заряда Угленита Э-6 2,4 кг в каждом шпуре. По представленной выше методике на различном расстоянии от торпедируемого шпура бурились рабочий и контрольный шпуры. В рабочий шпур подавался газ под давлением, в контрольном шпуре определялся расход. Результаты исследований по определению радиуса зоны эффективного трещинообразования представлены в таблице 1.

В тех же рабочих шпурах проводился контроль эффективности торпедирования массива. Результаты проведенных исследований по оценке эффективности торпедирования массива представлены в таблице 2.

Таблица 1

Результаты исследований газопроницаемости пород

\begin{tabular}{|c|c|c|c|}
\hline $\begin{array}{c}\text { Расстояние от } \\
\text { торпедируемого шпура, м }\end{array}$ & 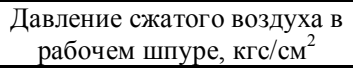 & $\begin{array}{c}\text { Объемный } \\
\text { расход газа, } \mathrm{cm}^{3} / \text { сек }\end{array}$ & $\begin{array}{c}\text { Коэффициент } \\
\text { газопроницаемости, мДарси }\end{array}$ \\
\hline \multicolumn{4}{|c|}{ в массиве до торпедирования } \\
\hline & 10 & 0,0072 & 0,002212 \\
\hline & 10 & 0,0064 & 0,001959 \\
\hline & 10 & 0,0314 & 0,009622 \\
\hline \multicolumn{4}{|c|}{ после торпедирования } \\
\hline 0,8 & 10 & 0,3092 & 0,09464 \\
\hline 1,0 & 10 & 0,4066 & 0,12447 \\
\hline 1,2 & 2 & 6,1227 & 61,84579 \\
\hline 1,3 & 10 & 5,4800 & 1,67738 \\
\hline 1,4 & 2 & 5,4691 & 55,24353 \\
\hline 1,5 & 10 & 0,0841 & 0,02574 \\
\hline 1,6 & 10 & 0,0314 & 0,00962 \\
\hline 1,8 & 10 & 0,2363 & 0,07232 \\
\hline
\end{tabular}

Таким образом, коэффициент газопроницаемости в массиве до торпедирования равен: $\mathrm{K}=(2,212+1,959+9,622) \times 10^{-3} / 3=4,05 \times 10^{-3}$ мДарси

Радиус зоны эффективного трещинообразования:

$$
\mathrm{R}_{\text {эф }}=0,9 *(1,5+1,8) / 2=1,485 \mathrm{M}
$$

Таблица 2

Результаты исследований воздухопоглощения

\begin{tabular}{|c|c|c|c|c|}
\hline $\begin{array}{c}\text { Расстояние от } \\
\text { торпедируемого шпура, } \\
\text { м }\end{array}$ & $\begin{array}{c}\text { Изменение объ- } \\
\text { ема, л }\end{array}$ & $\begin{array}{l}\text { Время, } \\
\text { мин }\end{array}$ & $\begin{array}{c}\text { Показатель воздухопоглоще- } \\
\text { ния, л/мин }\end{array}$ & $\begin{array}{c}\text { Среднее значения пока- } \\
\text { зателя, л/мин }\end{array}$ \\
\hline \multicolumn{5}{|c|}{ до торпедирования } \\
\hline & 0,5 & 25 & 0,020 & \multirow{3}{*}{0,03} \\
\hline & 1 & 22 & 0,045 & \\
\hline & 0,5 & 20 & 0,025 & \\
\hline \multicolumn{5}{|c|}{ после торпедирования } \\
\hline 0,8 & 4 & 14 & 0,286 & \multirow{8}{*}{2,76} \\
\hline 1,0 & 4 & 12 & 0,333 & \\
\hline 1,2 & 2 & 0,1 & 20,000 & \\
\hline 1,3 & 3 & 9,5 & 0,316 & \\
\hline 1,4 & 2 & 2 & 1,000 & \\
\hline 1,5 & 0,5 & 20 & 0,025 & \\
\hline 1,6 & 0,5 & 23 & 0,022 & \\
\hline 1,8 & 2 & 20 & 0,100 & \\
\hline
\end{tabular}

Таким образом, соотношение средних показателей воздухопоглощения до и после торпедирования составляет:

$K_{\text {эф }}=2,76 / 0,03=91,54>1,5$.

Как видно из таблицы 2, коэффициент воздухопоглощения в контрольном шпуре на расстоянии 1,5 м от торпедируемого шпура имеет значение близкое к среднему значению коэффициента воздухопоглощения в нетронутом массиве. Следовательно, максимальный радиус трещинообразования не превышает 1,5 м.

\section{Заключение}

В результате проведения шахтных экспериментальных исследований по определению радиуса зоны эффективного трещинообразования по карналлит-галитовому слою пласта калийно-магниевых солей получены следующие результаты:

2. Установлено, что по коэффициенту воздухопоглощения пород максимальный радиус эффективного трещинообразования для карналлит-галитовых пород не превышает 1,5 м. 
3. При расчетах параметров торпедирования для безопасной проходки выработок комбайновым способом по карналлит-галитовым породам в условиях шахтного поля Гремячинского ГОКа величину радиуса эффективного трещинообразования вокруг шпурового заряда и использовании в качестве ВВ «Угленита Э-6» следует принимать не более 1,5 м.

\title{
Исследование выполнено при финансовой поддержке РФФИ в рамках научного проекта № 18-05-00371 а «Газодинамические явления на калийных рудниках: внезапные разрушения кровли и почвы выработок»
}

\section{БИБЛИОГРАФИЧЕСКИЙ СПИСОК}

1. Андрейко С.С. Газодинамические явления в калийных рудниках: методы прогнозирования и способы предотвращения: учеб. пособие. - Пермь: Изд-во. ПГТУ, 2007. - 208 с.

2. Нестерова С.Ю. Технология дегазации выбросоопасных пород при механизированной выемке карналлита // Изв. вузов. Горн. журн. - 2008. - № 8. - С. 47-52.

3. Технологический регламент механизированной отработки карналлитового пласта В на руднике СКРУ-1 ПАО «Уралкалий»: утв. ПАО «Уралкалий». - Пермь; Березники, 2018. - 48 с.

4. Нестерова С.Ю., Андрейко С.С. Технология дегазации выбросоопасного массива при механизированной добыче карналлита // Естественные и технические науки. - 2017. - № 2. - С. 64-67.

5. Механический эффект подземного взрыва / под общ. ред. М.А. Садовского. - М.: Недра. - 1971. - 224 с.: ил.

6. Родионов В.Н., Сизов И.А., Цветков В.М. Основы геомеханики. - М.: Недра, 1986. - 301 с.: ил.

7. Адушкин В.В., Спивак А.А. Геомеханика крупномасштабных взрывов. - М.: Недра.-1993.-318 с.: ил.

8. Мальцев В.М. Расчет радиуса зоны трещинообразования одиночного удлиненного заряда ВВ // Стратегия и процессы освоения георесурсов: материалы ежегод. науч. сес. ГИ УрО РАН по результатам НИР в 2009 г. - Пермь, 2010. - С. 220-222.

\section{ПОВЫШЕНИЕ СОХРАННОСТИ КАРТОФЕЛЯ ПРИ ХРАНЕНИИ В АТМОСФЕРЕ, ФОРМИРУЕМОЙ ПРИ ПОМОЩИ ПРИРОДНЫХ КАЛИЙНЫХ СОЛЕЙ}

\author{
Г.З. ФАЙНБУРГ, А.Г. ИСАЕВИЧ \\ Горный институт УрО РАН, г. Пермь
}

Аннотация: Представлены результаты экспериментальных исследований 1990-1991 гг. по использованию калийной соли для специальной обработки воздуха и поддержания требуемых параметров микроклимата в поверхностном хранилище картофеля. Получено, что сохраняемость картофеля возросла почти в полтора раза, снизились потери и заболеваемость картофеля.

Ключевые слова: калийная соль, аэроионы, хранение картофеля.

\section{ВВЕДЕНИЕ}

Традиционное использование калийных солей ( $\mathrm{KCl}$ - хлорида калия) в качестве сырья для производства минеральных удобрений общеизвестно. Традиционное использование каменной (поваренной) соли ( $\mathrm{NaCl}$ - хлорида натрия) в пищевых целях также известно всем. Также оба соединения широко используют как исходное сырье для химической промышленности.

В настоящее время все более необходимым становится комплексное использование и основных месторождений, и добываемых руд, и собственно калийно-магниевых солей. Необходимо, среди прочего, отказаться от сложившегося экстенсивного пути развития производства калийных удобрений, качественно изменить формы, методы и объемы традиционной горнодобывающей деятельности, шире использовать весь спектр уникальных свойств калийных солей.

Благотворное действие калия на живой организм хорошо известно, и именно поэтому его используют как удобрение.

Известны и бактерицидные свойства растворов хлоридов натрия (используется для хранения соленых продуктов) и калия, например, в сильвинитовых спелеокамерах [1-5].

Заметим, что бактерицидная способность калийной соли выражена сильнее, чем у натриевой из-за большей химической активности калия по сравнению с натрием. Кроме того, наличие в калийных солях кроме основного элемента ${ }^{39} \mathrm{~K}$ природного радиоактивного изотопа ${ }^{40} \mathrm{~K}$ создает естественную ионизацию среды также неблагоприятную для бактерий. Все это дает основания для широкого использования калийных солей как естественных антисептиков и очистителей воздуха при хранении картофеля. 